\title{
Intravenous Leiomyomatosis: Molecular and Cytogenetic Analysis of a Case
}

\author{
Bradley J. Quade, M.D., Ph.D., P. Dal Cin, D. M. Neskey, S. Weremowicz, C. C. Morton \\ Departments of Pathology (BJQ, PDC, SW, CCM) and Obstetrics, Gynecology, and Reproductive Biology \\ (DMN, CCM), Brigham and Women's Hospital and Harvard Medical School (BJQ, PDC, SW, CCM), \\ Boston, Massachusetts
}

\begin{abstract}
Apart from its hormone responsiveness, little about the pathobiology of intravenous leiomyomatosis (IVL), a rare smooth muscle proliferation, is known. We investigated the cytogenetics and molecular biology of IVL in a 40-year-old female who presented with an abrupt onset of dyspnea. In addition to the intracaval tumor mass composed of histologically benign smooth muscle, four distinct retroperitoneal "fibroids" were cytogenetically investigated. An identical abnormal karyotype, 45,XX,der(14)t(12;14)(q15;q24),22 , was observed in all five specimens. Fluorescence in situ hybridization revealed three copies of HMGIC (alias HMGA2), two on the normal chromosomes 12 at $12 q 15$, as well as another on the $\operatorname{der}(14)$ in the breakpoint region, suggesting that the $12 \mathrm{q}$ breakpoint occurred 5' (centromeric) to HMGIC (HMGA2), as has been frequently observed in uterine leiomyoma. Such similarity in chromosomal rearrangements suggests that there may be a pathogenetic relationship between IVL and uterine leiomyomata with $t(12 ; 14)$. Skewed $\mathrm{X}$ inactivation was observed in each tumor sample, but not in the myometrium. In each tumor, the lower molecular weight allele of HUMARA was nonrandomly inactivated. This pattern of $\mathrm{X}$ inactivation is most consistent with origin from a single transformation event, and in this regard, IVL more closely resembles disseminated peritoneal leiomyomatosis than typical uterine leiomyomata.
\end{abstract}

KEY WORDS: Clonality, Cytogenetics, HMG proteins Intravenous leiomyomatosis, Leiomyoma, Leiomyosarcoma, Vascular invasion.

Mod Pathol 2002;15(3):351-356

Copyright (C) 2002 by The United States and Canadian Academy of Pathology, Inc.

VOL. 15, NO. 3, P. 351, 2002 Printed in the U.S.A.

Date of acceptance: November 19, 2001.

This project was supported in part by grants from the American Cancer Society (RPG CNE-100283 to BJQ) and the National Cancer Institute (CA78895 to CCM).

Address reprint requests to: Bradley J. Quade, M.D., Ph.D., Department of Pathology, Brigham and Women's Hospital, 75 Francis Street, Boston, MA 02115; e-mail: bquade@rics.bwh.harvard.edu; fax: (617) 975-0864.
Intravenous leiomyomatosis (IVL) is one of several rare and unusual disorders of uterine smooth muscle proliferation characterized by quasimalignant behavior. Intravenous leiomyomatosis is defined by histologically benign smooth muscle growth within vascular spaces from intrauterine venules to the right heart $(1,2)$. When limited to the pelvis, this disorder manifests as "wormlike" protrusions of tumor emanating from veins at the parametrial margin of hysterectomy specimens. This disorder may be asymptomatic or present as a pelvic mass like typical uterine leiomyomata. Cardiopulmonary insufficiency may result when the right atrium is involved. Apart from the hemodynamic and embolic consequences, intravenous leiomyomatosis is clinically benign and treatable by extirpation (3-6). Recurrence is uncommon (7-10). Intravenous leiomyomatosis rarely is coincident with benign metastasizing leiomyoma in the lung (11).

The neoplastic smooth muscle of intravenous leiomyomatosis resembles that of benign uterine leiomyomata and may include the same histological variants found in the uterus (12). Furthermore, the neoplastic smooth cells of IVL express estrogen and progesterone receptors, and tumor growth appears to respond to hormonal manipulation (13-15). In contrast to other benign and malignant uterine smooth muscle tumors, little about the molecular pathology of IVL is known. This paper focuses on determining the clonal origin and the cytogenetic relationship of IVL with uterine leiomyomata.

\section{CASE REPORT}

A 40 -year-old gravida 6 , para 4 woman with hypertension and diet-controlled diabetes presented with an abrupt onset of dyspnea on exertion. Evaluation by transesophageal echocardiography and computerized tomography revealed the presence of a tumor mass extending from the pelvis, through the inferior vena cava and right atrium, across the tricuspid valve, and filling the right ventricle. In the first of two procedures, the intracaval and intracardiac masses were extirpated after institution of car- 
diopulmonary bypass. A pulmonary ventilationperfusion imaging study after the first procedure showed defects consistent with tumor embolism. The uterus and a dozen retroperitoneal masses were removed in the second procedure.

\section{MATERIALS AND METHODS}

\section{Cytogenetic and Molecular Cytogenetic Studies}

GTG-banded chromosomes were analyzed from short-term (2-day) cultures of four distinct retroperitoneal masses, as well as the intracaval mass, the small parametrial tumorlet, and the intrauterine leiomyoma, using established methods in our laboratory. Fluorescence in situ hybridization (FISH) with biotin and digoxigenin-labeled cosmids 142H1 and 27E12 (16), which map to the $5^{\prime}$ and 3 ' regions of HMGIC (alias $H M G A 2$, as proposed in [17]), respectively, was performed on metaphase spreads prepared from the intracaval mass as described elsewhere (18). In other FISH experiments, biotin-labeled bacterial artificial chromosome (BAC) clone 475C2 (Research Genetics), located within $R A D 51 B$ at $14 \mathrm{q} 24$, was used (19).

\section{Clonality Analysis by \\ $\mathrm{X}$-Chromosome Inactivation}

We determined clonality by analyzing the pattern of $\mathrm{X}$ chromosome inactivation at the androgen receptor gene (HUMARA) located on chromosome $\mathrm{X}$ band q11.2-q12 (20-23). DNA for the clonality assay was extracted from normal tissue and from four tumor tissues using a minor modification of a procedure from Strauss (24) in which the DNA extraction buffer was substituted by $50 \mathrm{~mm}$ Tris, $\mathrm{pH}$ 8.5; $0.5 \%$ Tween $20 ; 1 \mathrm{~mm}$ of EDTA, and $20 \mu \mathrm{g} / \mu \mathrm{L}$ of proteinase K. Approximately $2 \mu \mathrm{g}$ of DNA was digested with $40 \mathrm{U}$ of $\mathrm{HhaI}$ for 3 hours at $37^{\circ} \mathrm{C}$, and the digestion was terminated by phenol-chloroform extraction, followed by ethanol precipitation at $-20^{\circ} \mathrm{C}$ overnight. Approximately $100 \mathrm{ng}$ of DNA (with and without prior HhaI digestion) was used for PCR amplification, and products were analyzed by nondenaturing acrylamide gel electrophoresis and autoradiography as described elsewhere (23).

Autoradiograms were digitized and the resulting uncompressed tagged image (TIFF) files quantitatively analyzed using Scion Image Release Beta Version 4.0.2 (Scion Corporation, Frederick, MD), a version of the NIH Image program ported to the Windows 9x operating systems (available at www.scioncorp.com). Skewing of $\mathrm{X}$ inactivation (\%Xi) was calculated according to the following equation:

$$
\% X i=\left(100 \times \frac{L M W^{+}}{L M W^{+} \times H M W^{+}}\right) \times\left(\frac{H M W^{-}}{L M W^{-}}\right),
$$

where $L M W^{+}, H M W^{+}, L M W^{-}$, and $H M W^{-}$represent the relative amounts of the low and high mo- lecular weight products with $(+)$ and without $(-)$ prior HhaI digestion (23). As the average ratio of PCR products before HhaI digestion for all samples was 1.02 , the equation was simplified accordingly.

\section{RESULTS}

\section{Pathological Features}

The intracaval and intracardiac tumors consisted of a long, cylindrical mass $(25 \mathrm{~cm}$ length $\times 3.5 \mathrm{~cm}$ in greatest diameter) with occasional branching protrusions that tapered at their termini, suggesting the impression of a vascular cast (Fig. 1). The cut surfaces were tan-white, firm, and bulging, and closely resembled those of typical intrauterine leiomyomata. Microscopic examination of hematoxylin and eosin-stained tissue sections revealed smooth muscle cells arranged predominantly in fascicles, but occasionally in a plexiform pattern. The neoplastic cells did not have significant proliferative activity, atypia, or necrosis, supporting the diagnosis of intravenous leiomyomatosis.

The hysterectomy specimen from the secondstage procedure was remarkable for several wormlike growths $(0.1-0.2 \mathrm{~cm}$ in diameter) and one tumorlet $(0.3 \mathrm{~cm}$ in diameter) present in several veins at parametrial cut surfaces bilaterally. Upon histological examination, these growths consisted of benign, but moderately hypercellular smooth muscle in venous spaces. Microscopic intravascular leiomyomatosis was also found deep within the myometrium, adjacent to a solitary $3.0-\mathrm{cm}$ intramuscular leiomyoma. This intramural leiomyoma had a variegated gray to pink, cut surface with focal gross hemorrhage that histologically appeared to be caused by extensive ischemic necrosis. No atypia or increased mitotic activity was noted in the thin rim of viable tumor. Direct continuity between this leiomyoma and intravenous leiomyomatosis could not be documented by dissection.

The retroperitoneal tumors consisted of multiple "fibroids," some of which were multinodular masses and others of which were solitary masses. They ranged in size from $3 \times 1 \times 2 \mathrm{~cm}$ to $10 \times 6 \times$ $5 \mathrm{~cm}$ and appeared to be covered in unremarkable peritoneum. Although grossly mimicking subserosal uterine leiomyomata, there was no connection between the masses and the uterus. The retroperitoneal tumors were histologically benign, and some nodules had plexiform features similar to the intracaval tumor. Interestingly, mature adipocytes, either individually or in small clusters, were admixed with neoplastic smooth muscle cells in occasional microscopic fields, suggesting the histological diagnosis of lipoleiomyoma in those fields. 


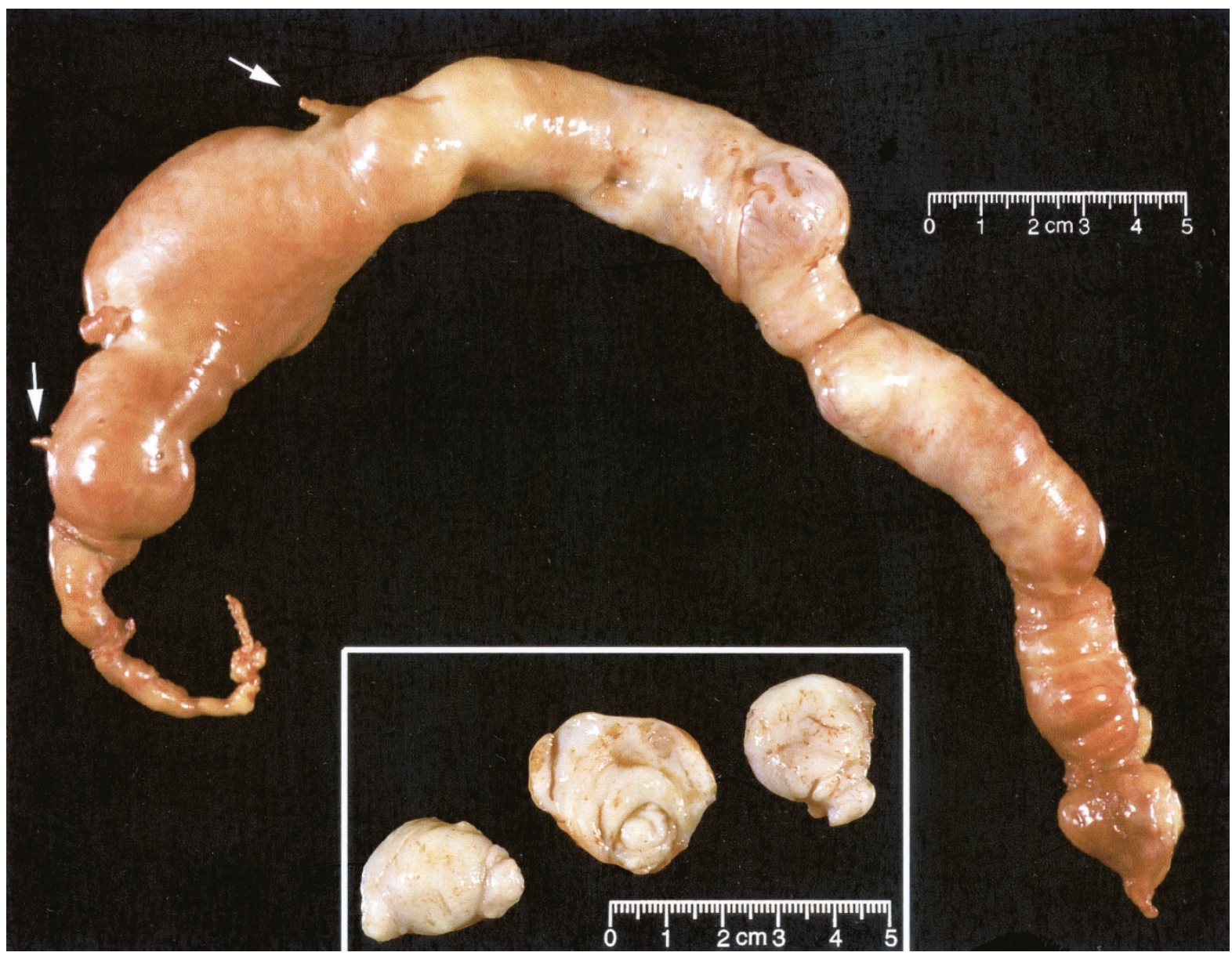

FIGURE 1. Gross appearance of intracaval smooth muscle tumor. The tapered terminus located on the left of the picture was removed from the heart. The tissue tags extending from the mass (arrows) were extensions into small feeding veins. The inset shows several cross-sections that resemble typical intrauterine leiomyomata.

\section{Cytogenetic and Molecular Cytogenetic Studies}

Cytogenetic analysis of the intracaval mass (Fig. 2) revealed a karyotype of $45, \mathrm{XX}, \operatorname{der}(14)(\mathrm{t}(12$; 14) (q15;q24),-22 in all metaphases. Identical karyotypes, i.e., 45,XX, $\operatorname{der}(14) \mathrm{t}(12 ; 14),-22$, were also observed in all four retroperitoneal and one parametrial specimens. Attempted cytogenetic analysis of the intramural leiomyoma was unsuccessful, presumably because of histologically confirmed necrosis. By fluorescence in situ hybridization (FISH) analysis of the intracaval tumor, both cosmids $(142 \mathrm{Hl}$ detected with avidin-FITC and 27E12 detected with anti-digoxigenin-rhodamine conjugate) hybridized to the der(14) chromosome and both apparently normal chromosomes 12, indicating that the chromosome 12 breakpoint occurred 5' (centromeric) to HMGIC (HMGA2). To test whether the rearrangement was similar to those observed in typical uterine leiomyomata, we hybridized tumor metaphases with probes (cosmid 27E12 detected with digoxigenin-rhodamine conjugate and BAC 475C2 detected with avidin-FITC) for HMGIC (HMGA2) and a RAD51B, which spans the breakpoint region on $14 \mathrm{q} 24$. On the $\operatorname{der}(14)$ chro- mosome, 27E12 and 475C2 were closely juxtaposed in metaphases prepared from the intracaval tumor.

\section{Clonality Analysis by \\ X-Chromosome Inactivation}

Both HUMARA alleles were visualized by presence of PCR products migrating slightly above the $234 \mathrm{bp}$ size marker, demonstrating heterozygosity for the androgen receptor polymorphism in this individual (Fig. 3). After HhaI digestion of the myometrial DNA sample, both PCR products were nearly equally abundant, consistent with random $\mathrm{X}$-chromosome inactivation in a polyclonal tissue. In contrast to the myometrium, amplification of sample from the caval mass and all three retroperitoneal masses after HhaI digestion produced more products from the lower molecular weight allele than from the upper molecular weight allele. Quantitative results are provided in Table 1. Such highly skewed X inactivation in each tumor specimen is evidence of monoclonal origin. The pattern of $\mathrm{X}$ inactivation favoring the same chromosome is con- 
14 der(14)

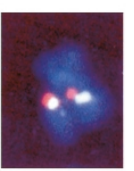

12

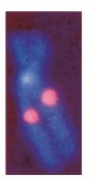

12
A

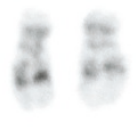

1212
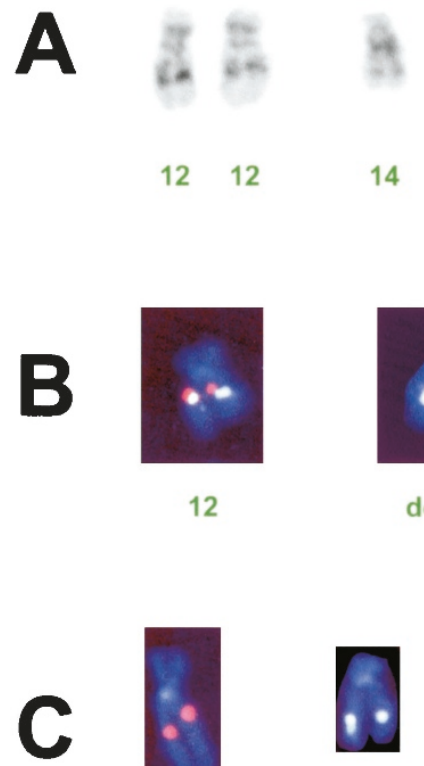

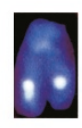

14

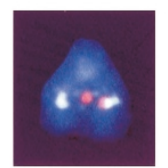

$\operatorname{der}(14)$

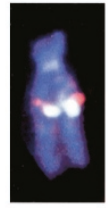

$\operatorname{der}(14)$
FIGURE 2. Cytogenetic analysis of intravenous leiomyomatosis. A partial GTG-banded karyotype (A) shows two normal chromosomes 12, one normal chromosome 14 , and an abnormal chromosome 14 derived from $\mathrm{t}(12 ; 14)(\mathrm{q} 15 ; \mathrm{q} 24)$. Metaphase chromosomes from the intracaval mass were hybridized with biotin-labeled cosmid $142 \mathrm{H1}$ and digoxigenin-labeled cosmid 27E12, which correspond to the 5' and 3' regions of HMGIC (HMGA2), respectively (Panel B), and detected with avidin-fluorescein isothiocyanate (FITC) and rhodamine-antidigoxigenin conjugates, respectively. The probes hybridized to both copies of chromosome 12 and the $\operatorname{der}(14)$ chromosome, indicating that the tumor has three copies of HMGIC (HMGA2) and distal 12q. Consistent co-localization of both cosmids shows that the chromosome 12 breakpoint falls outside of HMGIC (HMGA2). Additional fluorescence in situ hybridization experiments were performed with digoxigeninlabeled cosmid 27E12 (detected with rhodamine-anti-digoxigenin conjugate) and biotin-labeled BAC 475C2 (detected with avidin-FITC conjugate), which corresponds to a chromosome 14 locus within $R A D 51 B(\mathbf{C})$. Close juxtaposition of these probes shows that the rearrangement in this case of intravenous leiomyomatosis involves the same regions of chromosomes 12 and 14 as those seen in typical uterine leiomyomata.

sistent with dissemination from a single transformation event.

\section{DISCUSSION}

Several uterine smooth muscle proliferations (viz., IVL, disseminated peritoneal leiomyomatosis, and benign metastasizing leiomyoma) are of interest because of their quasimalignant behaviors. In addition to vascular invasion, these "clinically benign" lesions also may manifest intraperitoneal and pulmonary metastasis. The molecular pathological basis of these behaviors has yet to be elucidated fully. For the first time, we have had the opportunity to compare the cytogenetic and molecular features of IVL with those of other benign and malignant smooth muscle tumors.

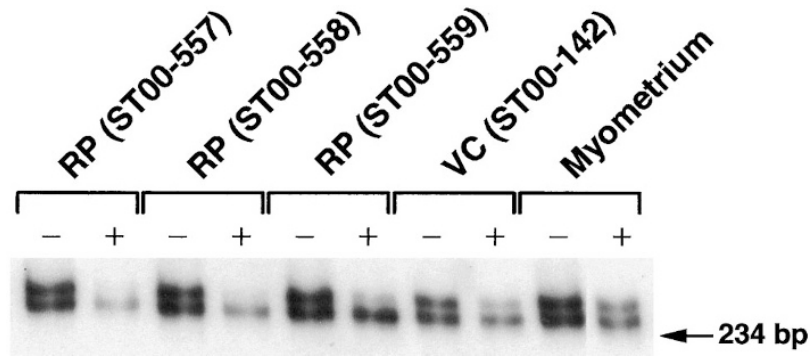

FIGURE 3. Analysis of clonality by polymerase chain reaction amplification of the HUMARA microsatellite polymorphism with (+) and without $(-)$ previous HhaI restriction digestion. DNA was extracted from frozen retroperitoneal (RP) and vena cava (VC) leiomyomatous growths and normal myometrium. No preferential X-chromosome inactivation was observed in normal myometrium, and nonrandom $\mathrm{X}$ inactivation was found in all leiomyomatous lesions.

TABLE 1. Determination of Clonality by Skewed Chromosome $X$ Inactivation

\begin{tabular}{lcr}
\hline \multicolumn{1}{c}{ Tissue } & Sample Number & $\% \mathrm{Xi}$ \\
\hline Myometrium & - & 61 \\
Intracaval tumor & ST00-142 & 74 \\
Retroperitoneal tumor & ST00-557 & 100 \\
Retroperitoneal tumor & ST00-558 & 100 \\
Retroperitoneal tumor & ST00-559 & 100 \\
\hline
\end{tabular}

A relatively simple consistent karyotype was observed in all analyzed samples of a IVL: partial trisomy $12 \mathrm{q} 15 \rightarrow$ qter, due to an unbalanced translocation between chromosomes 12 and 14, and monosomy 22 . The uniformity of these aberrations among all of the lesions is consistent with uniclonal origin. Clonality analysis based on the pattern of $\mathrm{X}$-chromosome inactivation also supports uniclonal origin in intravenous leiomyomatosis. Although it seems likely that the intravenous leiomyomatosis originated from the single intramural leiomyoma, extensive necrosis precluded our testing of this hypothesis.

The cytogenetic abnormalities of typical uterine leiomyomata and leiomyosarcomas have been extensively reported. In general, complex numerical and structural aberrations have been observed in leiomyosarcomas; in contrast, simple chromosomal aberrations are typical of uterine leiomyomata (25). The balanced translocation (12;14)(q14-15;q23-24) is one of the most commonly observed rearrangements, either as the sole abnormality or in addition to other chromosomal abnormalities, in uterine leiomyoma. The breakpoint on 12q14-15 typically falls 5' to HMGIC (HMGA2) and results in aberrant expression of this gene (unpublished data). An unbalanced rearrangement producing der $(14) \mathrm{t}(12 ; 14)$ has been previously, albeit rarely, reported in pulmonary chondroid hamartoma (26) and uterine leiomyomata (27-29). Interestingly, two of the three cases with a solitary der (14) also have partial or complete monosomy $22(27,28)$. 
Presence of a similar chromosomal mechanism (i.e., $\mathrm{t}(12 ; 14)$ and a breakpoint 5 ' to HMGIC (HMGA2)) in this case of IVL suggests that the pathogenetics of IVL is related to typical uterine leiomyoma and unrelated to leiomyosarcoma. The focal presence of adipocytic differentiation in this case and more prominent fatty differentiation in another case is also interesting as it highlights the role of $H M G I C$ (HMGA2) in normal and neoplastic fat cell proliferation (30). The contribution of HMGIC (HMGA2) to the phenotypic features of intravenous leiomyomatosis merits further investigation.

The independent clonal origin of multiple leiomyomata within a given uterine corpus have been well demonstrated by X-chromosome inactivation analysis using two different polymorphic markers, namely glucose-6-phospate dehydrogenase $(G 6 P D)$ isoenzymes and a microsatellite within the androgen receptor $(20,31)$. Malignant and another quasimalignant smooth muscle proliferations (disseminated peritoneal leiomyomatosis) appear to arise from single transforming events (23). These $\mathrm{X}$-chromosome inactivation results, supported by our cytogenetic results, show that IVL is uniclonal. The additional peritoneal masses in this case are likely the consequence of intravascular dissemination within the pelvic veins. In contrast to their cytogenetic similarity, a uniclonal origin distinguishes intravenous leiomyomatosis from multiclonal uterine leiomyomata.

The paradox of intravascular and disseminated peritoneal leiomyomatosis is that they are more cytogenetically similar to benign leiomyomata but display growth characteristics somewhere between those of benign and malignant smooth muscle tumors. The mechanistic basis of these clinically benign behaviors appears to be distinct from simple chromosomal changes such as $\mathrm{t}(12 ; 14)$. How other cytogenetic (e.g., partial or full deletion of one copy of chromosome 22) or submicroscopic changes contribute to intravascular or intraperitoneal dissemination remains to be determined. Understanding these unique smooth muscle proliferations, however, may provide a model for understanding these malignant behaviors found in tumors with more complex pathogenetics.

\section{REFERENCES}

1. Zaloudek C, Norris HJ. Mesenchymal tumors of the uterus. In: Kurman RJ, editor. Blaustein's pathology of the female genital tract. 4th ed. New York: Springer-Verlag; 1994. p. 487-528.

2. Clement PB. Intravenous leiomyomatosis of the uterus. Pathol Annu 1988;23(2):153-83.

3. Harris LM, Karakousis CP. Intravenous leiomyomatosis with cardiac extension: tumor thrombectomy through an abdominal approach. J Vasc Surg 2000;31:1046-51.

4. Rosenberg JM, Marvasti MA, Obeid A, Johnson LW, Bonaventura M. Intravenous leiomyomatosis: a rare cause of right sided cardiac obstruction. Eur J Cardiothorac Surg 1988;2:58-60.

5. Timmis AD, Smallpeice C, Davies AC, Macarthur AM, Gishen P, Jackson G. Intracardiac spread of intravenous leiomyomatosis with successful surgical excision. N Engl J Med 1980; 303:1043-4.

6. Wakiyama H, Sugimoto T, Ataka K, Yamashita C, Tsuji Y, Nakagiri $\mathrm{K}$, et al. Intravenous leiomyomatosis extending into the right ventricular cavity: one-stage radical operation using cardiopulmonary bypass-a case report. Angiology 2000; 51:505-9.

7. Evans AT III, Symmonds RE, Gaffey TA. Recurrent pelvic intravenous leiomyomatosis. Obstet Gynecol 1981;57:260-4.

8. Cooper MM, Guillem J, Dalton J, Marboe CC, Corwin S, Todd GJ, et al. Recurrent intravenous leiomyomatosis with cardiac extension. Ann Thorac Surg 1992;53:139-41.

9. Mulvany NJ, Slavin JL, Ostor AG, Fortune DW. Intravenous leiomyomatosis of the uterus: a clinicopathologic study of 22 cases. Int J Gynecol Pathol 1994;13:1-9.

10. Gawne-Cain ML, Wilson AG, Corbishley C, Keating V, Joseph AE. Case report: intravenous leiomyomatosis, an unusual cause of intracardiac filling defect. Clin Radiol 1995;50:123-5.

11. Koh DM, Burn PR, King DM. Benign metastasizing leiomyoma with intracaval leiomyomatosis. Br J Radiol 2000;73: 435-7.

12. Clement PB, Young RH, Scully RE. Intravenous leiomyomatosis of the uterus. A clinicopathological analysis of 16 cases with unusual histologic features. Am J Surg Pathol 1988;12: 932-45.

13. Heinonen PK, Taina E, Nerdrum T, Taulaniemi E, Aine R, Helve O, et al. Intravenous leiomyomatosis. Ann Chir Gynaecol 1984;73:100-3.

14. Konrad P, Mellblom L. Intravenous leiomyomatosis. Acta Obstet Gynecol Scand 1989;68:371-6.

15. Tresukosol D, Kudelka AP, Malpica A, Varma DG, Edwards CL, Kavanagh JJ. Leuprolide acetate and intravascular leiomyomatosis. Obstet Gynecol 1995;86:688-92.

16. Schoenmakers EF, Wanschura S, Mols R, Bullerdiek J, Van den $\mathrm{BH}$, Van de Ven WJ. Recurrent rearrangements in the high mobility group protein gene, HMGI- C, in benign mesenchymal tumours. Nat Genet 1995;10:436-44.

17. Bustin M. Revised nomenclature for high mobility group (HMG) chromosomal proteins. Trends Biochem Sci 2001;26: 152-3.

18. Weremowicz S, Morton CC. Is HMGIC rearranged due to cryptic paracentric inversion of $12 \mathrm{q}$ in karyotypically normal uterine leiomyomas? Genes Chromosom Cancer 1999;24: 172-3.

19. Pedeutour F, Quade BJ, Sornberger K, Tallini G, Ligon AH, Weremowicz S, et al. Dysregulation of HMGIC in a uterine lipoleiomyoma with a complex rearrangement including chromosomes 7, 12, and 14. Genes Chromosom Cancer 2000;27:209-15.

20. Mashal RD, Fejzo ML, Friedman AJ, Mitchner N, Nowak RA, Rein MS, et al. Analysis of androgen receptor DNA reveals the independent clonal origins of uterine leiomyomata and the secondary nature of cytogenetic aberrations in the development of leiomyomata. Genes Chromosom Cancer 1994;11:1-6.

21. Mutter GL, Chaponot ML, Fletcher JA. A polymerase chain reaction assay for non-random $\mathrm{X}$ chromosome inactivation identifies monoclonal endometrial cancers and precancers. Am J Pathol 1995;146:501-8.

22. Mutter GL, Boynton KA. X chromosome inactivation in the normal female genital tract: implications for identification of neoplasia. Cancer Res 1995;55:5080-4.

23. Quade BJ, McLachlin CM, Soto-Wright V, Zuckerman J, Mutter GL, Morton CC. Disseminated peritoneal leiomyomatosis. Clonality analysis by $\mathrm{X}$ chromosome inactivation and 
cytogenetics of a clinically benign smooth muscle proliferation. Am J Pathol 1997;150:2153-66.

24. Strauss W. Preparation of genomic DNA from mammalian tissue. In: Ausubel F, Brent R, Kingston R, Moore D, Seidman J, Smith J, Struhl K, editors. New York: Wiley Interscience, 1994: 2.2.1-2.2.2.

25. Mitelman F. Catalog of chromosome aberrations in cancer 1998. New York: Wiley; 1998: Vol. 1 on CD-ROM.

26. Kazmierczak B, Meyer-Bolte K, Tran KH, Wockel W, Breightman I, Rosigkeit J, et al. A high frequency of tumors with rearrangements of genes of the HMGI(Y) family in a series of 191 pulmonary chondroid hamartomas. Genes Chromosom Cancer 1999;26:125-33.

27. Hu J, Surti U. Subgroups of uterine leiomyomas based on cytogenetic analysis. Hum Pathol 1991;22:1009-16.
28. Rein MS, Friedman AJ, Barbieri RL, Pavelka K, Fletcher JA, Morton CC. Cytogenetic abnormalities in uterine leiomyomata. Obstet Gynecol 1991;77:923-6.

29. Hayashi S, Miharu N, Okamoto E, Samura O, Hara T, Ohama K. Detection of chromosomal abnormalities in uterine leiomyoma using conventional cytogenetic method and interphase fluorescence in situ hybridization. Cancer Genet Cytogenet 1996;89:98-104.

30. Hashiguchi J, Ito M, Kishikawa M, Sekine I, Kase Y. Intravascular leiomyomatosis with uterine lipoleiomyoma. Gynecol Oncol 1994;52:94-8.

31. Townsend DE, Sparkes RS, Baluda MC, McClelland G. Unicellular histogenesis of uterine leiomyomas as determined by electrophoresis by glucose-6-phosphate dehydrogenase. Am J Obstet Gynecol 1970;107:1168-73. 